\title{
Does Extensive Reading Improve EFL learners' Processing Ability?
}

\author{
Abbas Ali Rezaee \\ Faculty of Foreign Languages and Literatures, University of Tehran (UT), Iran \\ Email: aarezaee@ut.ac.ir \\ Saeed Nourzadeh \\ Faculty of Persian Literature and Foreign Languages, Allameh Tabataba'i University, Iran \\ Email: saeednourzadeh@yahoo.com
}

\begin{abstract}
Reading experts usually agree upon the fact that Extensive Reading (ER), meaning engaging learners in reading long passages, say stories, can improve students' various aspects of proficiency. The aim of the present study is to investigate whether ER can promote bottom-up and top-down processing capacities employed by advanced learners of English as a Foreign Language (EFL) when reading second language (L2) texts. In this study, bottom-up and top-down processing capacities have been operationalized as L2 learners' ability to answer local and global reading comprehension questions, respectively. To achieve this aim, two intact advanced classes, one as the experimental group $(n=26)$ and the other as the control group $(n=25)$, were selected to be included in the present study. The learners in the experimental group participated in an ER course in which each learner was required to read four story books during four weeks (i.e., one story book per week) at their homes. The findings of the study indicated that participation in ER courses promotes Iranian advanced EFL learners' bottom-up and top-down processing capacities. The overall findings have implications for $\mathrm{L} 2$ reading comprehension classes and assessment.
\end{abstract}

Index Terms - extensive reading, bottom-up processing, top-down processing, local questions, global questions

\section{INTRODUCTION}

Many second language (L2) reading researchers agree that one of the most effective ways for learners to improve different aspects of their proficiency in an L2 is to engage in what is called Extensive Reading (Cho \& Krashen, 1994; Day \& Bamford, 1998; Leung, 2002; Mason \& Krashen, 1997; Rodrigo, Krashen \& Gribbons, 2004). Extensive reading (ER) could simply be defined as reading a lot of materials for pleasure with no concern for accountability (Mason \& Krashen, 1997). Further, it is also necessary that readers have control over what they want to read (Day \& Bamford, 2002).

ER activities are believed to increase learners' motivation (Day \& Bamford, 1998; Takase, 2002) self-confidence (Arnold, 2009) and positive attitudes towards L2 reading (Camiciottoli, 2001; Leung, 2002). They also expose learners to comprehensible input which is proposed by some L2 theorists to be the primary mover of the process of second language acquisition. Krashen is known to be the most famous of these theorists who claims in many places (e.g., 1989, and 2004) that the causal factor in the acquisition of an L2 is the input that the learner receives from his surrounding environment, whether classroom or natural setting, given that the input is comprehensible. Perhaps, the most economical way of providing this comprehensible input is ER, especially in a foreign language context where learners usually do not have enough access to authentic spoken input assumed necessary for the progression of L2 competence forward.

On the other hand, due to their levels of proficiency, language learners usually use either top-down processing or bottom-up processing or, in many cases, both to get meaning out of what they are reading. In top-down processing "contextual factors such as socio-cultural knowledge and task assessment" are employed for interpreting discourse. While, "bottom-up processing is the productive or interpretive choices one makes regarding words, phrases, and sentence structures comprising the discourse of the task" (Celce-Murcia \& Olshtain 2005, p. 733). Top-down processing is activated when the reader tries to call for his world knowledge for comprehending what he is reading; whereas, bottom-up processing happens when the reader restricts himself solely to the text at hand. In many cases readers, particularly experienced ones utilize both processing models to get as much as they can from a text in the shortest time available. The question, however, is whether ER helps readers improve their top-down and bottom-up processing. The present study is geared towards investigating the improvement of top-down and bottom-up processing models through encouraging advanced readers to read a sizeable number of passages.

\section{BACKGROUND OF THE STUDY}


In order to become competent in an L2, one needs to possess linguistic and pragmatic knowledge of that language. As to the linguistic aspect, he should know the sounds of the language, the writing system, grammatical structures, words, and discourse. Regarding the pragmatic aspects, language functions, variations, and interactional skills are necessary. With respect to reading successfully in an L2, good knowledge of vocabulary and grammar play the most important roles. ER, that is, encouraging language learners to read as much as possible, has been shown to enhance these two aspects whereby competence is improved. In this regard, a number of investigations have been conducted to show the influence of ER on the development of vocabulary and grammar.

Much attention has been paid to the positive influences of ER on the incidental acquisition of L2 vocabulary (e.g., Horst, 2005; Kweon \& Kim, 2008; Leung 2002; Pigada \& Schmitt, 2006; Pitts, White, \& Krashen, 1989, to name just a few). This type of vocabulary learning is called 'incidental' because the learner's attention is focused on something other than the words to be learned, i.e., on getting meaning out of a text (Gass, 1999). For instance, Leung (2002) reports a case study of ER where L2 vocabulary knowledge of her subject, referred to as Wendy, "improved by $23.5 \%$ " in one month" (p. 70), as measured by a modified version of Paribakht and Wesche's (1997) scale of vocabulary knowledge. Wendy's total score, out of 200, rose from $28.5 \%$ to $35.2 \%$ from the pretest to the posttest, which had a maximum score of 196. This finding has been corroborated by classroom-based ER research (e.g., Horst, 2005; Kweon \& Kim, 2008). Horst's (2005) participants, for example, succeeded to acquire over half of the unknown L2 words they encountered in the ER materials. On the other hand, as far as the long-term storage of incidentally acquired words is concerned, Kweon and Kim (2008) provided supporting evidence that vocabulary gains during ER were retained over a 4-week interval after the immediate posttest, with retention having an interaction with frequency with which an L2 word would be used in L2 texts.

One benefit of incidental vocabulary acquisition is that expanding lexical knowledge through reading will benefit reading itself because an expanded L2 lexicon makes the process of getting meaning out of the text easier and more enjoyable. As Eskey (2005) puts it:

It is now well understood that the best (some would argue the only) way to acquire the extensive vocabulary required for reading widely in a second language is reading itself, and it is equally well understood that a prerequisite for such reading is an extensive vocabulary - a classic chicken and egg situation. (p. 567)

Furthermore, words learned through L2 reading comprehension activities are more prone to be mentally activated during on-line, communicative language use situations. This may be attributed to the hypothesis that words learned incidentally through ER are restructured and accommodated into the L2 learner's interlanguage system because they have been learned via a language learning activity, i.e., ER, which resembles real language uses. Then, an incidental approach to L2 vocabulary instruction and acquisition is preferred over more intentional techniques such as bilingual word lists and controlled vocabulary exercises because, even at an intuitional level, it seems to be clear that knowledge of a word includes more than simply a link between the word's form and its meaning.

In contrast to incidental vocabulary acquisition, not much research about the effects of L2 reading comprehension activities on the acquisition of L2 grammatical rules has been done. The reason for this is that the learning of grammatical structures is more complex than vocabulary learning and that this complexity in grammar learning necessitates the conscious noticing (Schmidt, 1990) to the target grammatical form to be learned. Thus, it is not surprising that, in the literature of SLA, more attention has been paid to the acquisition of L2 grammatical forms as a result of explicit instruction of them (e.g. Doughty, 1991; Norris \& Ortega, 2000) than to their acquisition through more direct, communicative approaches, including ER.

However, two studies in the L2 reading literature have found evidence in support of the positive effects of ER on L2 grammatical acquisition. Stokes, Krashen, and Kartchner (as cited in Krashen, 2004) found that the extent of L2 Spanish learners' engagement in ER, or what they called Free Voluntary Reading, was a powerful predictor of their ability to use Spanish subjunctive verbs in real communicative situations, even if they did not know the metalinguistic rule governing the use of subjunctive verbs in Spanish. This finding showing the positive effects of ER on L2 grammatical development was interesting because the other variables included in the study such as "the amount of formal study of Spanish, the amount of formal study specifically aimed at the subjunctive, and how long subjects had lived in a Spanish-speaking country" (Krashen, 2004, p. 10) did not correlate with learners' knowledge of subjunctive verbs.

Subjunctive verbs are not the only verb form that could be acquired subconsciously as a by-product of engaging in ER. L2 English relative clauses are, too, subject to such learning and evidence for this has been found in Lee, Krashen, and Gribbons (as cited in Krashen, 2004). However, to come up with firm conclusions about the influences ER exerts on L2 syntactic acquisition, more systematic studies have to be undertaken to determine whether the positive findings observed in the aforementioned studies might be generalized to other L2 syntactic structures or to other L2 learner populations as well.

Moreover, Krashen (1989) found evidence that reading activities can help L2 learners develop their spelling skills in the second language in a way that overrides more "skill-based" approaches to the instruction of L2 spelling such as words lists, spelling rules, and exercises. In addition to linguistic benefits, ER could be hypothetically thought to develop a reader's ability to process a text. Supporting evidence on this hypothesis has been found in relation to L2 reading fluency (Bell, 2001; Iwahori, 2008; Tanaka \& Stapleton, 2007) and strategies (Hayashi, 1999). In fact, it is the 
aim of the present investigation to find out whether and to what extent such a hypothesis is logical and correct. Specifically, two L2 reading comprehension processes are of significance for the purposes of this study, namely, bottom-up and top-down processing.

\section{B. Bottom-up and Top-down Processing}

A distinction is often made between top-down and bottom-up processes that are thought to contribute to the extraction of meaning from both spoken and written text. Top-down processing mainly refers to the use of "contextual factors such as socio-cultural knowledge and task assessment for producing or interpreting discourse, whereas bottomup processing is the productive or interpretive choices one makes regarding words, phrases, and sentence structures comprising the discourse of the task" (Celce-Murcia \& Olshtain 2005, p. 733). In other words, top-down processing happens when the reader, or the listener, activates whatever information he has about the world around him, the topic of the passage, and its discourse patterns to help him comprehend the text he is reading. Bottom-up processing, on the other hand, means using the linguistic repertoire of lexical items, structural patterns, and orthographic/phonological knowledge we have at our disposal to decode the text meaning.

Some psycholinguists draw out attention to the levels at which these two kinds of processing come about. For instance, Carroll (2008) defines bottom-up processing as a model "which proceeds from the lowest level to the highest level of processing in such a way that all of the lower levels operate without influence from the higher levels" and topdown as a model in which "information at the higher levels may influence processing at the lower levels" (p. 56). This means that reading comprehension is not a one-shot process, and the reader goes into different levels based on the text and extralinguistic needs that he encounters as he reads throughout the passage. Thus, it can be assumed that the distinction between bottom-up and top-down processing is not a dichotomy partly because of the nature of the comparative adjectives higher and lower used by Carroll (2008). They, instead, form a continuum which ranges from the lowest level to the highest level of top-down resources. Anyway, it is appropriate to maintain the distinction between the two kinds of processing since, at any moment of the reading task, the processing is assumed to lean towards one of the two end extremes of bottom-up top-down continuum.

As far as the operationalization of bottom-up and top-down processing for research purposes is concerned, Shohamy and Inbar (1991) make a distinction between local and global questions by which bottom-up and top-down processing could be assessed. This distinction is originally based on the distinction that Van Dijk and Kintsh (as cited in Shohamy \& Inbar, 1991) made between two types of comprehension strategies, namely, local and global strategies. Shohamy and Inbar (1991) assert that local strategies are in need of attention to relations and links between facts while global ones require focus on the global coherence.

Local strategies are those which require attention to relations and links between the facts denoted by local clauses and sentences; and b) global/macro-strategies are those which require a focus on the overall coherence, gist, or topic of a text. The local comprehension units are subordinate to the macro-units. (p. 26)

It can be understood from this definition that the distinction between local and global questions is very much closely related to the one already made between bottom-up and top-down processing and the difference between the two distinctions is only a matter of terminology not content. This could be explicitly shown by referring to Tsui and Fullilove (1998) who used the same distinction of local and global questions in their study.

A gap is observed in the area of research on local and global comprehension questions since both aforementioned studies (i.e., Shohamy \& Inbar, 1991; Tsui \& Fullilove, 1998) used the distinction with respect to L2 listening comprehension tests. Therefore, it seems that L2 reading comprehension has not found its place in this area of research. Furthermore, these two studies investigated these two types of comprehension questions from a perspective different from the one intended in this study. Shohamy and Inbar (1991) used them for validation of L2 listening comprehension tests, while Tsui and Fullilove (1998) used them to find out whether or not they could operate as a discriminator of test takers' performance on an L2 listening comprehension test. What is under-researched is the question of how correct responses to these question types can be possibly enhanced. This study is an attempt to examine one of these possibilities; that is, whether engaging in an ER program can promote the amount of bottom-up and top-down processing and, as a result, L2 learners' correct responses to local and global reading comprehension questions.

The present study has been designed to investigate whether participation in ER programs can cause to improve advanced learners' bottom-up and top-down processing capacities. Therefore, the following two research questions have been formulated.

1. Do advanced EFL learners' bottom-up processing capabilities improve as a result of participation in ER programs?

2. Do advanced EFL learners' top-down processing capabilities improve as a result of participation in ER programs?

\section{THE PRESENT STUDY}

\section{A. Design}

The research design used in the present study is a quasi-experimental one with a pre-test to assure the equality of groups prior to the instructional treatment, i.e., the ER course, and a post-test to determine the results of the instructional treatment after its implementation. The differences between the pre- and post-test results are of importance to determine whether the ER course benefits those participants who attend it in contrast to those who do not. Two intact 
classes, one as the experimental group $(n=26)$ and the other as the control group $(n=25)$, were asked to take a measure of reading comprehension ability as the pre-test. After the treatment, the learners took the same measure of L2 reading comprehension ability once more as a post-test.

\section{B. Participants}

Fifty one students from two intact advanced classes acted as participants in the present study from a private language institute in Tehran, Iran. Both classes were held on even days, with one of the classes being held in the morning and the other class in the afternoon and both were taught by the same teacher who described her approach to language teaching as a mixture of different techniques she believed to be appropriate based on her previous experiences in language teaching. As there might have been the risk of learners' interaction with each other after each session, there was a fidelity check to make sure that the learners would not meet each other. This was the reason behind choosing the two classes, one of which was held in the morning and the other one in the afternoon. Moreover, the learners came from different parts of the city with no or very little chance of knowing each other. As to the teacher, it should be stated that she was a very experienced one who could easily take care of her variety in teaching the two classes. This, in turn, eliminated the risk of using the same or even similar procedure in the two classes.

The participants could be described as pre-TOEFL learners as the semester following the one in which they participated in the present study was designed to prepare the participants for taking the TOEFL. All participants were female, and had been learning English as a Foreign Language between two to five years. All were native speakers of Persian, and aged between 17 to 38 years old. One of the classes was randomly selected as the experimental group ( $n=$ $26)$ and the other as the control group $(n=25)$.

\section{Materials and Instrumentation}

Simplified story books and fictions. Twenty nine books were selected as the ER materials to be read by the experimental group as homework. Each participant from the experimental group was required to read four books during four weeks, i.e., one book per week, based on their own choice from among the ER collection. The collection consisted of simplified story books and also of fiction books. Simplified story books included a range of books that have been adapted to learners from different L2 proficiency levels, with the adaptation / simplification usually occurring in the areas of vocabulary and syntax. Those included in the present study were chosen from Levels 5 and 6 of the Readers Series which has simplified story books at six levels, extending from Beginner (Level 1) to Advanced (Levels 6). Fiction books, on the other hand, included those story books that have not been written for educational purposes and, therefore, are genuine as far as their linguistic forms and structures are concerned.

The books were chosen from these three different levels of difficulty in vocabulary and structures to allow the learners to select those books that they could read efficiently based on their conception of their own proficiency in the English language. Further, attempts were made to include those books that were interesting in their topics and content. In fact, the assumption that the selected books had interesting topics and content was frequently confirmed, informally, by the participants of the experimental group during the study. The above measures were consistent with the assumption in the ER literature that L2 readers should, to some extent, have control over what they read in the L2 (Day \& Bamford, 2002) and were a breakthrough to the limitation of the previous studies of ER which required the participants to read a prescribed set of ER materials (e.g., Brown, Waring, \& Donkaewbua, 2008; Kweon \& Kim, 2008; Pitts, White, \& Krashen, 1989).

The measure of $\mathbf{L} 2$ reading comprehension. Four major steps were taken to construct a measure of L2 reading ability that could reliably and validly assess the participants' ability to answer local and global reading comprehension four-option multiple-choice questions:

Step one. The readability of each text in the reading section that would come at the end of the last six chapters of the classroom textbook was estimated using Fog Index of Reliability. The last six chapters of the textbook were chosen for this purpose because they were to be covered during the term. The passages had readability indices ranging from 18.92 to 23.13 (Mean $=21.35$ and Standard Deviation =1.48). This readability range was set as the criterion for the selection of texts that would comprise the measure of L2 reading ability utilized in the present study.

Step two. At this stage, seven passages were selected for inclusion in the test. The passages were chosen from available books in the market that had been written specifically for the purpose of preparing prospective TOEFL test takers. Only those passages were included in the measure that had a reliability index falling within the readability range criterion set at step one above, with two of the passages of the test exceeding this range criterion with minor deviations of .39 and .25 of a readability unit. The passages had readability indices ranging from 19.03 to 23.52 , with the indices having a mean of 21.88 and a standard deviation of 1.88 . The final format of the measure consisted of 52 multiplechoice items that were to be answered by participants in 60 minutes.

Step three. The constructed measure of L2 reading ability, then, was submitted to two assessors to code each item in the measure either as local or global. Both assessors were PhD students of TEFL at the University of Tehran with native-like English language proficiency and were asked to make judgments either because of their expertise in L2 reading research or language testing issues. Coding reliability coefficient between the two assessors was .94 , a high reliability indicating the appropriateness of the theoretical distinction between local and global reading comprehension 
questions. The three questions on which the assessors did not have agreement were judged again by the present researchers themselves.

Step four. Although the validity of the constructed measure of L2 reading ability for the research purpose was, to some extent, guaranteed by adapting the readability index of each passage in the test to the participants' L2 reading proficiency, it was also necessary to demonstrate that the test was a reliable measure of L2 reading ability as well. Therefore, fourteen students who were at the same proficiency level as the participants in the present study were asked to take the test in a pilot study. The resulting reliability coefficient using KR-21 was estimated to be .74, which could be said to be an acceptable reliability coefficient for further analyses to be carried out based on the measure of L2 reading ability.

As far as the scoring of the measure was concerned, the participants' correct answer to each item was given one credit. Therefore, the total score for the whole test was 52, with the total score of 24 for the set of local questions and 28 for the set of global questions. To counterbalance the guessing effect that could emerge from a participant finding the correct answer by chance, it was decided to use a 'correction for guessing' procedure. Therefore, one-third of a credit was deduced from the participant's final score for any wrong answer.

\section{Procedure}

The whole research project took four weeks, out of the six weeks (three sessions per week) during which the learners of both classes attended the language course they had enrolled in. The students in the experimental group were asked if they were ready to volunteer for participation in the study. The researchers explained to them the purpose of the study to be carried out. They were informed of the potential benefits that participation in such a study could have for the development of their English language proficiency.

Both groups took the measure of L2 reading ability as the pre-test in the same day. At the end of the same session, the students from the experimental group were asked to choose, from among the collection of simplified story books and fictions, one book that appealed to their interests. They were told that they were required to read the book in the week ahead of them before bringing it back to the classroom on the first session of the next week.

The above treatment procedure took four weeks during which each participant from the experimental group read four books, i.e., one book per week. The students of the control group, on the other hand, were not exposed to the ER course, and were only required to participate in the pre-test and post-test sessions. Those participants from the experimental group who did not succeed to cover the self-selected book completely at the assigned time period were required to attend make-up sessions on which they read the rest of the book in the institute. To make sure that the participants in the experimental group had read their self-selected books, each of them was asked some questions, by the researchers or the teacher, about the content of the book they had just taken back to the classroom. This procedure took about several minutes in the case of any single participant from the experimental group. This questioning procedure, however, did not seem to breach the unaccountability criterion of ER (Mason \& Krashen, 1997) because it did not have high-stakes consequences (e.g., final scores). After the finish of the instructional treatment, both the experimental and the control groups took the measure of L2 reading ability once more as the post-test.

\section{RESULTS}

All the participants took the 24 local reading comprehension test items. As shown in Table 1, the students in the experimental group had a mean of 9.00 , with a standard deviation of 2.83 , while those in the control group could obtain a mean of 8.59, with the scores having a standard deviation of 3.13. The results of an independent-samples $t$-test indicated that there was no statistically significant difference in the pre-test performance of the two groups' participants with respect to local questions; $t(49)=.495, p<.05$, Sig. (2-tailed) $=.623$.

TABLE 1

DESCRIPTIVE STATISTICS OF THE EXPERIMENTAL AND THE CONTROL GROUPS' PERFORMANCES ON THE PRE-TEST
\begin{tabular}{|l|l|l|l|l|l|}
\hline Group Variable & N & Min & Max & M & SD \\
\hline Experimental Group & 26 & 4.67 & 15.67 & 9.00 & 2.83 \\
\hline Control Group & 25 & 3.67 & 14.33 & 8.59 & 3.13 \\
\hline
\end{tabular}

The post-test mean scores of the two groups with respect to local questions were analyzed to trace the potential benefits ER had for the promotion of L2 learners' ability to answer local reading comprehension questions correctly. Table 2 demonstrates the mean scores and standard deviations of the experimental group $(\mathrm{M}=10.80, \mathrm{SD}=2.95)$ and the control group $(\mathrm{M}=9.08, \mathrm{SD}=2.36)$. Independent-samples $t$-test was conducted to find out whether there was a statistically significant difference between the means of the two groups as a result of the experimental group participating in the ER treatment. The results confirmed the hypothesis that the EFL learners' ability to answer local reading comprehension questions had enhanced by engaging them in ER programs; $t(49)=2.287, p<.05$, Sig. (2-tailed) $=.027$. The effect size of the difference was .096 which was an indication that effect of ER on L2 learners' correct responses to local items was a moderate one. 
TABLE 2

DESCRIPTIVE STATISTICS OF THE EXPERIMENTAL AND THE CONTROL GROUPS' PERFORMANCES ON THE POST-TEST

\begin{tabular}{|l|l|l|l|l|l|}
\hline Group Variable & N & Min & Max & M & SD \\
\hline Experimental Group & 26 & 6.33 & 17.00 & 10.80 & 2.95 \\
\hline Control Group & 25 & 5.00 & 12.33 & 9.08 & 2.36 \\
\hline
\end{tabular}

As to the 28 items asking global question, analyses on the scores obtained by the students were done. Table 3 shows the descriptive statistics of the pre-test scores with respect to these questions. The experimental group had a mean score of 9.39 with a standard deviation of 2.39 whereas the control group had a mean of 10.05 with a standard deviation of 2.72. Independent-samples $t$-test was conducted to see whether the difference between the means of the two groups in the pre-test was significant or not. The results of the $t$-test showed that the experimental and the control groups had been on a par, with respect to their correct responses to global questions, prior to the implementation of the ER program as there is no statistically significant difference between their mean scores; $t(49)=-.935, p<.05$, Sig. $(2$-tailed $)=.354$.

TABLE 3

DESCRIPTIVE STATISTICS OF THE EXPERIMENTAL AND THE CONTROL GROUPS' PERFORMANCES ON THE PRE-TEST

\begin{tabular}{|l|l|l|l|l|l|}
\hline Group Variable & N & Min & Max & M & SD \\
\hline Experimental Group & 26 & 5.67 & 15.00 & 9.39 & 2.39 \\
\hline Control Group & 25 & 6.33 & 16.33 & 10.05 & 2.72 \\
\hline
\end{tabular}

The results of the statistical analyses of the experimental and control groups' post-test performances on the global questions as a set of the measure of L2 reading ability are shown in table 4 below. The experimental group gained a mean of 11.95 with a standard deviation of 2.89. The control group, on the other hand, obtained a mean score of 10.03 and a standard deviation of 2.62. The results of independent-samples $t$-test indicated that the difference between the mean values of the two groups' was statistically significant; $t(49)=2.484, p<.05$, Sig. $(2$-tailed) $=.016$. The magnitude of the difference was calculated to be moderate (eta squared $=.112$ ). The preceding statistics indicates that the effects of the ER course on top-down processing capacities were larger than its effects on bottom-up processing capacities even though in both cases the effects were statistically significant.

TABLE 4

DESCRIPTIVE STATISTICS OF THE EXPERIMENTAL AND THE CONTROL GROUPS’ PERFORMANCES ON THE POST-TEST

\begin{tabular}{|l|l|l|l|l|l|}
\hline Group Variable & $\mathrm{N}$ & Min & Max & M & SD \\
\hline Experimental Group & 26 & 6.67 & 17.00 & 11.95 & 2.89 \\
\hline Control Group & 25 & 6.33 & 15.33 & 10.03 & 2.62 \\
\hline
\end{tabular}

\section{DISCUSSION}

As correct responses to local reading comprehension questions depend mostly upon the processing of lower-order linguistic forms and structures, positive evidence that ER increases L2 readers' correct responses to such questions implies that learners' L2 knowledge will develop as a result of engagement in ER courses. This finding is consistent with those findings, in the field of L2 reading research, that are interpreted as evidence on the positive role of ER in the expansion of L2 vocabulary, grammar, and spelling knowledge. For example, Robb and Susser's (1989) study demonstrated that their ER group members who were required to read 500 pages as a minimum were more able at guessing the meanings of unknown words, a strategy that seems to be necessary for answering text-based reading comprehension questions including local items. Furthermore, besides the development of the ability to guess the meanings of unknown L2 words, a host of researchers have found that L2 reading comprehension in general and ER in particular can expand learners' L2 vocabulary knowledge (Krashen, 1989; Kweon \& Kim, 2008) beyond the temporary recognition of word meanings.

On the other hand, as far as the acquisition of L2 grammatical structures is concerned, Lee, Krashen, and Gribbons (1996) as well as Stokes, Krashen, and Kartchner (1998) found evidence in support of the relationship between engagement in ER programs and the use/acquisition of particular L2 grammatical structures. Lee, et al (as cited in Krashen 2004) found that those learners participating in ER activities had a better opportunity to acquire L2 English relative clauses. Consistent with this evidence is Stokes, et al's (as cited in Krashen, 2004) finding that there is a correlation between L2 Spanish learners' use of Spanish subjunctive verbs for communicative purposes and the extent to which they are engaged in ER programs.

Moreover, Krashen (1989) found evidence that reading activities can help L2 learners develop their spelling skills in the second language in a way that overrides more "skill-based" approaches to the instruction of L2 spelling such as words lists, spelling rules, and exercises. This last finding, however, does not seem to be able to explain for so much variance in the development of bottom-up processing capacities in the case of the participants of the present study as it can be argued that the L2 spelling complexities that advanced L2 learners confront do not usually pose a problem to their comprehension of an L2 text. It is logical to claim that advanced L2 learners do not explicitly focus their attention on sound-grapheme correspondences when comprehending an L2 text, a strategy that seems insufficient and unnecessary when the purpose is to understand an L2 text rather than to analyze it linguistically. 
All of these findings provide evidence that ER contributes to the acquisition of different aspects of a second language. Therefore, the increase in the experimental group's correct responses to local questions can be explained by gains in theses aspects, save spelling, that result from participation in ER courses and that, in turn, contribute to the bottom-up processing of L2 texts. The benefits of ER for the development of reading comprehension processes was not, of course, limited to bottom-up processing as the findings of the study demonstrated that the experimental group's responses to global questions increased by participating in the ER program. Further, the size of this increase was larger than that occurring with respect to local questions even though in both cases the increase could reach statistical significance.

The question is how ER activities improve these higher-order top-down processes in L2 readers' minds. Possible justifications for this improvement are the development of working memory for L2 reading comprehension, the development of the ability to recognize discourse features of L2 texts, and the expansion of the learners' knowledge of the second language. First, Palladino, Cornoldi, De Beni and Pazzaglia (2001) contend that, in L1 reading comprehension, the optimal comprehension of a text requires an updating working memory system hold the relevant information for processing while discarding the irrelevant reading stimuli. The role of this updating working memory system in L2 reading can hypothetically be claimed to be more prominent in the case of top-down processing than bottom-up processing since the former is usually involved in the comprehension of supra-sentential meanings; that is, those meanings that traverse the boundaries of single sentences. This traversing across sentences to understand those meanings that have not been stated linguistically in the text requires the assignment of more working memory resources. Therefore, some variance in the increase in the number of experimental group's correct responses to global items in the present study can hypothetically be attributed to the development of the L2 reading working memory capacity that has resulted from participation in the ER treatment.

Second, related to the reading comprehension working memory capacity is an awareness of the discourse features of texts to be read. In fact, as Perfetti and Goldman (1976) empirically demonstrate, linguistic knowledge and the efficient distribution of working memory capacities are two main variables that contribute to the processing of text organization and text discourse features. On the other hand, it is documented in L2 reading research that L2 readers' familiarity with how texts in the second language are organized discursively contributes to the comprehension processes of those texts (Jiang \& Grabe, 2007). Therefore, some variance in the development of Iranian EFL learners' top-down processing capacities in this study is hypothetically attributable to the familiarization of the participants with the discourse features of L2 English texts as a result of participation in the ER course.

Finally, expansion of the knowledge of English as a second language may partially explain the increase in the advanced EFL learners' correct responses to global questions. This hypothesis seems justifiable since, as documented in the literature of L2 reading and listening research, bottom-up and top-down processing are but two extremes of the same processing continuum (Grabe, 1991; Lesgold \& Perfetti, 1978). That is, at any moment of comprehension processing, bottom-up and top-down processing are employed synchronously, with one extreme of the continuum being dominant. Therefore, lower-order linguistic forms and structures that are the single major factor in bottom-up processing operations during reading comprehension have also a contributory role in top-down processing, indicating that the development of top-down processing capacities has, to some extent, been influenced by the development of different aspects of the English language as a result of participation in the ER treatment.

There exists a unanimous agreement among ER researchers that the longer an ER course is implemented, the more conspicuous its effects are on the development of different aspects of an L2 (Green, 2005; Krashen, 2004; Renandya, 2007). Therefore, the pedagogical implications of ER can be said to be more far-reaching than what the present study would be able to demonstrate if more classroom time is to be devoted to ER programs. However, even within a short period of time (i.e., four weeks) and with a limited number of books assigned to each participant in the experimental group (i.e., four books), the results of the present study seems astonishing and therefore, supportable implications can be derived from them for pedagogical purposes.

ER can be used for the development of L2 reading processes that usually defy direct instruction because of their complexity or being so inseparable that any pedagogical attempt to isolate them for teaching may lead to undesirable results. ER, however, provides a natural context for the development of these processes in L2 readers. Further, it is suggested that learners' motivation to read in the L2 be enhanced by means of different instructional techniques so that the time they devote to reading extensively in the L2 would be increased. This, in turn, will lead to the development of different components of an L2 which can be used for language skills beyond L2 reading.

From an assessment perspective, involving prospective test-takers in ER programs can help them perform better in local and global reading comprehension items of measures of L2 proficiency. Further, the resulting development of different aspects of the L2 as a consequence of participation in ER activities can help prospective test-takers perform better in other subtests of measures of L2 proficiency such as those of L2 lexical and grammatical knowledge as well. Thus, it is suggested that ER activities be included in those educational programs which intend to prepare L2 learners for taking measures of L2 proficiency.

It is important to pay attention to Green's (2005) warning that "it is a fundamental misconception to see it [i.e., ER] as a 'stand-alone' component" (p. 308). On the other hand, focus on strategies-based approaches to L2 reading instruction is valued because many researchers have found that the instruction on L2 reading strategies help learners become better readers of an L2 (e.g., Carrell, Pharis, \& Liberto, 1989; Macaro \& Erler 2008; Raymond, 1993). Then, 
ER programs and strategies-based approaches to L2 reading instruction can be used in a complementary fashion in L2 reading classes so that the ultimate results of these classes for the development of L2 reading processing capacities can be optimized.

\section{CONCLUSION}

At the end, it is necessary to mention that most studies suffer from certain shortcomings and limitations. The present study is not an exception. Some of the limitations can provide the necessary grounds for further investigation. First, the present study did not include a measure of general L2 proficiency even though the two groups were of equal pretreatment status with respect to local and global reading comprehension questions. Studies should be carried out to see whether the observed effects of ER on the development of L2 reading processing capacities is a function of L2 reading comprehension or a function of general proficiency in the L2. Second, it is not possible, in the present study, to determine whether the factors listed as likely explanations of the development of top-down processing capacities play the role attributed to them since no operationalization of them was included in the study. They have been suggested here only as tentative, not conclusive, explanations as to the development of top-down processing capacities. Further investigation is required to determine whether or not they have such a function and, if so, to determine their exact contributions to the development of L2 reading processing capacities. Finally, long-term measures should be incorporated in studies of this kind to see whether the observed effects of ER are retained over time and beyond the immediate posttest.

\section{REFERENCES}

[1] Arnold, N. (2009). Online extensive reading for advanced foreign language learners: An evaluation study. Foreign Language Annals, 42, 340-366.

[2] Bell, T. (2001). Extensive reading: Speed and comprehension. The Reading Matrix, 1, 1-13. http://www.readingmatrix.com/archives.html (accessed 12/4/2006).

[3] Brown, R., Waring, R., \& Donkaewbua, S. (2008). Incidental vocabulary acquisition from reading, reading-while-listening, and listening to stories. Reading in a Foreign Language, 20(2), 136-163. http://nflrc.hawaii.edu/rfl/October2008/brown/brown.html (accessed 25/6/2010).

[4] Camiciottoli, B. C. (2001). Extensive reading in English: Habits and attitudes of a group of Italian university EFL students. Journal of Research in Reading, 24, 135-153.

[5] Carrell, P. L., Pharis, B. G., \& Liberto, J. C. (1989). Metacognitive Strategy training for ESL reading. TESOL Quarterly, 20, 463-494.

[6] Carroll, D. W. (2008). Psychology of language ( $5^{\text {nd }}$ ed.). Toronto: Thomson Nelson.

[7] Celce-Murcia, M., \& Olshtain, E. (2005). Discourse-based approaches: A new framework for second language teaching and learning. In E. Hinkel (Ed.), Handbook of research in second language teaching and learning (pp. 729-741). Mahwah, New Jersey: Lawrence Erlbaum associates.

[8] Cho, K.-S., \& Krashen, S. D. (1994). Acquisition of vocabulary from the Sweet Valley Kids series: Adult ESL acquisition. Journal of Reading, 37(8), 662-667.

[9] Day, R., \& Bamford, J. (1998). Extensive reading in the second language classroom. Cambridge: Cambridge University Press.

[10] Day, R., \& Bamford, J. (2002). Top ten principles for teaching extensive reading. Reading in a Foreign Language, 14(2), 136141. http://nflrc.hawaii.edu/rfl/October2002/day/day.html (accessed 10/12/2008).

[11] Doughty, C. (1991). Second language instruction does make a difference: Evidence from an empirical study of ESL relativization. Studies in Second language Acquisition, 13, 431-469.

[12] Eskey, D. E. (2005). Reading in second language. In E. Hinkel (Ed.), Handbook of research in second language teaching and learning (pp. 563-579). Mahwah, New Jersey: Lawrence Erlbaum associates.

[13] Gass, S. (1999). Discussion: Incidental vocabulary learning. Studies in Second Language Acquisition, 21(2), $319-333$.

[14] Grabe, W. (1991). Current developments in second language reading research. TESOL Quarterly, 25, 375-406.

[15] Green, C. (2005). Integrating extensive reading in the task-based curriculum. ELT Journal, 59, 306-311.

[16] Hayashi, K. (1999). Reading strategies and extensive reading in Efl classes. RELC Journal, 30, 114-132.

[17] Horst, M. (2005). Learning L2 vocabulary through extensive reading: A measurement study. The Canadian Modern Language Review, 61, 355-382.

[18] Iwahori, Y. (2008). Developing reading fluency: A study of extensive reading in EFL. Reading in Foreign Language, 20(1), 70-91. http://nflrc.hawaii.edu/rfl/April2008/iwahori/iwahori.html (accessed 15/1/2009).

[19] Jiang, X., \& Grabe, W. (2007). Graphic organizers in reading instruction: Research findings and issues. Reading in a Foreign Language, 19(1), 34-55. http://nflrc.hawaii.edu/rfl/April2007/jiang/jiang.html (accessed 12/4/2009).

[20] Krashen, S. D. (1989). We acquire vocabulary and spelling by reading: Additional evidence for the input hypothesis. The Modern Language Journal, 73, 440-464.

[21] Krashen, S. D. (2004). The power of reading: Insights from the research ( $2^{\text {nd }}$ ed.). Portsmouth, NH: Heinemann.

[22] Kweon, S.-O., \& Kim, H.-R. (2008). Beyond raw frequency: Incidental vocabulary acquisition in extensive reading. Reading in a Foreign Language, 20 (2), 191-215. http://nflrc.hawaii.edu/rfl/October2008/kweon/kweon.html (accessed 14/8/2009).

[23] Lee, Y. O., Krashen, S. D., \& Gribbons, B. (1996). The effect of reading on the acquisition of English relative clauses. ITL: Review of Applied Linguistics, 113-114, 263-273.

[24] Lesgold, A. M., \& Perfetti, C. A. (1978). Interactive processes in reading comprehension. Discourse processes, 1, 323-336.

[25] Leung, C. Y. (2002). Extensive reading and language learning: A diary study of a beginning learner of Japanese. Reading in Foreign Language, 14 (1), 66-81. http://nflrc.hawaii.edu/rfl/April2002/leung/leung.html (accessed 10/8/2008). 
[26] Macaro, E., \& Erler, L. (2008). Raising the achievement of young-beginner readers of French through strategy instruction. Applied Linguistics, 29, 90-119.

[27] Mason B., \& Krashen, S. D. (1997). Extensive reading in English as a foreign language. System, 25, 91-102.

[28] Norris, J. M., \& Ortega, L. (2000). Effectiveness of L2 instruction: A research synthesis and quantitative meta-analysis. Language Learning, 50, 417-528.

[29] Palladino, P., Cornoldi, C., De Beni, R., \& Pazzaglia, F. (2001). Working memory and updating processes in reading comprehension. Memory \& cognition, 29, 344-354.

[30] Paribakht,T. S., \& Wesche, J. (1997). Vocabulary enhancement activities and reading for meaning in second language vocabulary acquisition. In J. Coady \& T. Huckin (Eds.), Second language vocabulary acquisition: A rationale for pedagogy (pp. 174-202). Cambridge: Cambridge University Press.

[31] Perfetti, C. A., \& Goldman, S. R. (1976). Discourse memory and comprehension skill. Journal of Verbal Learning and Verbal Behavior, 14, 33-42.

[32] Pigada, M., \& Schmitt, N. (2006). Vocabulary acquisition from extensive reading: A case study. Reading in Foreign Language, 18(1), 1-28. http://nflrc.hawaii.edu/rfl/April2006/pigada/pigada.html (accessed 15/4/2009).

[33] Pitts, M., White, H., \& Krashen, S. D. (1989). Acquiring second language vocabulary through reading: A replication of the Clockwork Orange study using second language acquirers. Reading in a Foreign language, 5(2), 271-275.

[34] Raymond, P. M. (1993). The effects of structure strategy training on the recall of expository prose for university students reading French as a second language. The Modern Language Journal, 77, 445-458.

[35] Renandya, W. A. (2007). The power of extensive reading. RELC Journal, 38, 133-149.

[36] Robb, T. N., \& Susser, B. (1989). Extensive reading vs. skills building in an EFL context. Reading in a Foreign Language, 5(2), 239-251.

[37] Rodrigo, V., Krashen, S. D., \& Gribbons, B. (2004). The effectiveness of two comprehensible-input approaches to foreign language instruction at the intermediate level. System, 32, 53-60.

[38] Schmidt, R. (1990). The role of consciousness in second language learning. Applied Linguistics, 11, 129-158.

[39] Shohamy, E., \& Inbar, O. (1991). Validation of listening comprehension tests: The effect of text and question type. Language Testing, 8, 23-40.

[40] Stokes, J., Krashen, S. D., \& Kartchner, J. (1998). Factors in the acquisition of the present subjunctive in Spanish: The rolw of reading and study. ITL: Review of Applied Linguistics, 121-122, 19-25.

[41] Takase, A. (2002). Motivation to read English extensively. Kansai University Forum for Foreign Language Education, 1, 1-16.

[42] Tanaka, H., \& Stapleton, P. (2007). Increasing reading input in Japanese high school EFL classrooms: An empirical study exploring the efficacy of extensive reading. The Reading Matrix, 7 (1), 115-131. http://www.readingmatrix.com/archives.html (accessed 24/11/2009).

[43] Tsui, A., B., M., \& Fullilove, J. (1998). Bottom-up or top-down processing as a discriminator of L2 listening performance. Applied Linguistics, 19, 432-451.

[44] Van Dijk, T., \& Kintsh, W. (1983). Strategies of discourse comprehension. New York: Academic Press.

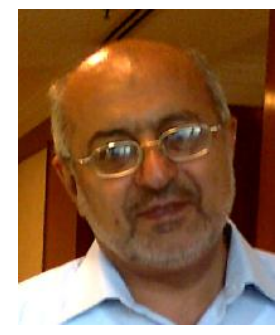

Abbas Ali Rezaee was born in Tehran, IR Iran, in 1956. He finished his MA in Teaching English as a Foreign Language (TEFL) in Tabiat Modarres University, Tehran, in 1989 and obtained his PhD in Applied Linguistics from the University of Exeter, England, in 2001.

He is currently a member of academic staff at the Department of English Language and Literature, Faculty of Foreign Languages and Literatures, University of Tehran. He has published many articles in national and international journals. He has taught specialized courses at BA, MA and PhD levels and has also supervised a large number of MA theses and $\mathrm{PhD}$ dissertation in language teaching and testing. His main research interests are Language Teaching, Language Testing, Discourse Analysis, ESP, and CALL.

Dr Rezaee is a member of the Teachers of English Language and Literature Society in Iran (TELLSI). He acts the reviewer of a number of domestic and international journals.

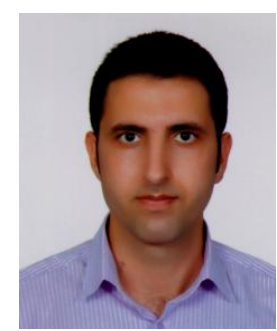

Saeed Nourzadeh was born in 1985 in Tehran. IR Iran. He holds an MA in TEFL from University of Tehran. At present, he is doing his PhD in TEFL at Allameh Tabataba'i University. He has been teaching English as a foreign language for several years, both at universities and language Institutes.

Mr. Nourzadeh's main areas of interest include 'second language reading comprehension processing', 'interlanguage pragmatics', 'identity in second language acquisition', and 'discourse analysis'. 